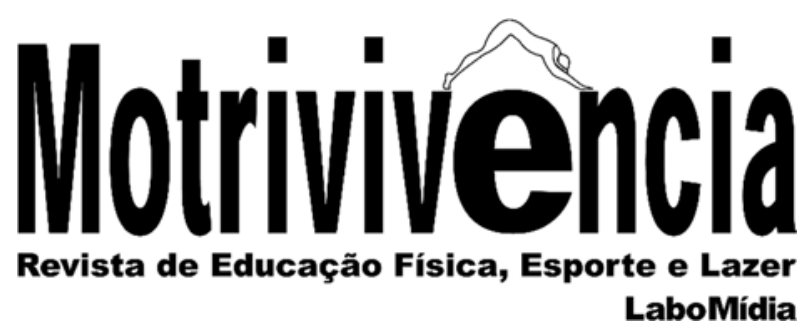

\title{
As referências de François Dubet nos periódicos científicos de Educação Física: limites e continuidades
}

\section{RESUMO}

O objetivo deste artigo é mapear a presença do sociólogo François Dubet na produção científica do campo da Educação Física (EF) e analisar de que maneira suas contribuições teóricas aparecem na área. Dubet é um sociólogo francês referência no mundo acadêmico atual. Este texto apresenta a descrição que Dubet faz sobre a "sociologia da experiência" e da escola democrática contemporânea, demonstrando uma possível desinstitucionalização deste espaço. O artigo se ocupará por realizar um levantamento bibliográfico nos principais periódicos da EF a fim de analisar aqueles artigos que referenciaram Dubet. Aponta, ainda, que há pouco diálogo entre a EF e o sociólogo francês, contudo, o campo parece iniciar uma aproximação crítica com as teorias de Dubet.

PALAVRAS-CHAVE: François Dubet; Educação física; Experiência; Epistemologia
Gabriel Carvalho Bungenstab Doutor em Sociologia

Universidade Estadual de Goiás - UEG Escola Superior de Educação Física e Fisioterapia - ESEFFEGO

Goiânia, Goiás, Brasil gabrielcarv@msn.com (ㄱ) https://orcid.org/0000-0002-3100-1538 


\title{
The references of François Dubet in the scientific journals of Physical Education: limits and continuities
}

\begin{abstract}
The objective of this article is to map the presence of the sociologist François Dubet in the scientific production of the field of Physical Education (EF) and analyze how their theoretical contributions flow to the area. Dubet is a French sociologist reference in the current academic world. It presents Dubet's description of the "sociology of experience" and the contemporary democratic school, demonstrating a possible deinstitutionalization of this space. The text will be responsible for carrying out a bibliographical survey in the main periodicals of the area in order to see those articles that referenced Dubet. He also points out that there is little dialogue between EF and the French sociologist, however, the field seems to initiate a critical approach to Dubet's theories
\end{abstract}

KEYWORDS: François Dubet; Physical education; Experience; Epistemology

\section{Las referencias de François Dubet en los periódicos científicos de Educación Física: límites y continuidades}

\section{RESUMEN}

El objetivo de este artículo es mapear la presencia del sociólogo François Dubet en la producción científica del campo de la Educación Física (EF) y analizar de qué manera sus contribuciones teóricas desaguan para el área. Dubet es un sociólogo francés referencia en el mundo académico actual. Se presenta la descripción que Dubet hace sobre la "sociología de la experiencia" y la escuela democrática contemporánea, demostrando una posible desinstitucionalización de este espacio. El texto se ocupará por realizar un levantamiento bibliográfico en los principales periódicos del área a fin de ver aquellos artículos que referenciaron a Dubet. Añade, además, que hay poco diálogo entre la EF y el sociólogo francés, sin embargo, el campo parece iniciar una aproximación crítica con las teorías de Dubet.

PALABRAS-CLAVE: François Dubet; Educacion fisica; Experiencia; Epistemología 


\section{INTRODUÇÃO}

O cenário pós-segunda guerra, como bem ressaltado por Nogueira (1990), provocou inúmeras mudanças educacionais no que tange a expansão massiva das taxas de escolarização dos países industrializados e, consequentemente, alavancou pesquisadores no âmbito da Sociologia da Educação. Essas pesquisas se voltaram para as desigualdades sociais diante do sistema de ensino. Quase sempre utilizando pesquisas quantitativas esses estudos tinham um caráter macroscópico visando mais a relação da instituição escolar com outras instituições e menos as atividades que ocorriam no cotidiano das escolas e das salas de aula. É nesse contexto que emerge o "paradigma da reprodução” que teve como expoente os estudos de Bourdieu e Passeron (2014).

Em contrapartida, na história recente da Sociologia da Educação (Física), tem se identificado um esforço de pensar a Educação (Física) para além das suas relações fixadas entre os dominantes, os dominados e as regulações. Esse deslocamento parece ser motivado pela ideia de também se considerar os agentes como capazes de transformarem e influenciarem as atividades escolares. Esses novos estudos têm se voltado para as descontinuidades e as atividades dos atores que vivenciam a escola e suas disciplinas.

No campo da Educação Física (EF) não é diferente. Além das já famosas contribuições do coletivo de autores (1992) e os estudos de caráter macrossocial de autores como Celi Taffarel e Silvio Gamboa, a área também passou a estudar e pesquisar com base em teorias microssociais. Como bem apontam Almeida, Bracht e Vaz (2012) é nesse bojo que acontece uma (re)descrição epistemológica, dividida basicamente entre os modernos e os “pós-modernos”. Atualmente a Educação Física vem sofrendo contribuições de inúmeros autores contemporâneos que não se encaixam em matrizes teóricas específicas. Essas contribuições vêm de diferentes pontos como, por exemplo, com: Zygmunt Bauman, David Le Breton, Merleau Ponty e François Dubet.

O objetivo deste artigo é refletir sobre as contribuições que o sociólogo François Dubet trouxe e ainda pode trazer para o campo da EF. ${ }^{1}$ Dubet é um sociólogo francês referência no mundo acadêmico atual. ${ }^{2}$ Suas contribuições teóricas e empíricas vão para além do seu campo de origem, influenciando, também, outros campos como o da Educação e EF. Como se dão as suas contribuições para nossa área? Segundo Wautier (2003) a sociedade atual está passando por inúmeras

$1 \mathrm{O}$ presente texto é resultado de estudos desenvolvidos no projeto de pesquisa intitulado “A presença da Sociologia contemporânea na produção científica da Educação Física brasileira no século XXI”. Este mesmo estudo também foi realizado com os sociólogos Zygmunt Bauman e Anthony Giddens (Bungenstab, 2018).

2 François Dubet possui inúmeras publicações, desde a década de 1970, que versam a respeito de problemáticas envolvendo a escola. Optou-se aqui em selecionar as obras que, para o presente texto, melhor dialogam com o debate proposto. 
transformações que afetam as relações dos indivíduos com as instituições tradicionais. Para a autora, as instituições não são mais capazes de responder aos anseios surgidos no contemporâneo e as explicações sociológicas, outrora facilmente aceitas, não conseguem responder aos dilemas cotidianos, inclusive aqueles referentes ao universo escolar e a EF. Dubet (1994, 2004, 2008, 2012), tem um modo particular de tratar esses temas ao reconhecer as instituições como espaços que produzem seus próprios conflitos no seio de uma sociedade, também, conflituosa.

Para tentar captar as possíveis contribuições do sociólogo francês para a EF é preciso, mesmo que sumariamente, compreender como ele desenvolve o seu conceito de “sociologia da experiência”. Esse conceito dará base para suas perspectivas sobre o que são as instituições. Ponto importante, também, é captar a ideia de Dubet a respeito da instituição escolar, pois, para ele, a escola na sociedade atual tem sofrido um processo de “desinstitucionalização”. Em virtude disso, o sociólogo francês vai propor modelos e reflexões para pensarmos a escola atual por um viés mais justo e igualitário, ou seja, menos conflituoso.

Este ensaio se ocupará por descrever sobre essas reflexões de Dubet, pautando-se por algumas de suas principais obras. Além de demonstrar suas contribuições para se pensar a escola atual, o ensaio também apontará de que maneira as obras de Dubet foram referenciadas no campo da EF no século XXI nos principais periódicos nacionais. Nesse sentido o leitor perceberá que o intuito é promover algumas reflexões sobre os usos das teorias deste sociólogo e fomentar outras maneiras de pensá-lo na área, sobretudo no que tange as novas problemáticas surgidas no contemporâneo.

A opção pelo recorte temporal a partir do século XXI se justifica na medida em que compreendemos que neste período histórico a produção do conhecimento e as potencialidades tecnológicas fizeram emergir o sentimento de descompasso e de insegurança diante de tudo já produzido até então. Nesse sentido, Santos (2010) nos convida a realizarmos perguntas simples no intuito de entendermos os rumos que a ciência tomou e irá tomar neste contexto. Assim, quais rumos foram e estão sendo tomados na relação que envolve a produção do campo da EF com aquela realizada pelos sociólogos contemporâneos, mais especificamente por François Dubet? (BUNGENSTAB, 2018, p. 778) O presente artigo é dividido em três momentos: 1) apresentação da teoria sociológica de Dubet; 2) mapeamento e análise da presença de Dubet na produção científica da EF a partir do século XXI e 3) conclusões.

\section{DUBET E A “EXPERIÊNCIA”}

Tanto o panorama sobre o que é a Sociologia da experiência como a própria experiência de Dubet enquanto professor dá subsídios para entender e discutir a respeito da sua obra e do seu 
posicionamento sobre a escola. Dubet foi influenciado, principalmente, pelos pensamentos de Georg Simmel e Alain Touraine. Essas influências irão compor seu posicionamento a respeito das noções de experiência social e lógicas de ação.

As lógicas de ação para Dubet (1994) dizem respeito às experiências e as relações que os indivíduos estabelecem com os sistemas reguladores que, hoje, se apresentam de forma muito mais heterogênea. Para ele, as lógicas de ação se relacionam com três tipos de situações sociais, quais sejam: sistema de integração (definem o indivíduo pelas suas pertenças de origem), sistema de competição (situações que envolvem interesses diversos dos atores) e sistema cultural (situação de subjetivação que está aliada a definições culturais).

Outros conceitos chaves também são interessantes para compreender a noção de experiência social em Dubet, são eles: sociedade, ações sociais e instituições. No período moderno, a noção de sociedade estava ligada à ideia de Estado-nação, fazendo com que a sociedade se tornasse um sistema onde os indivíduos interagiam de forma regulada, pautados pela racionalidade, pela divisão do trabalho e pelas relações sempre formalizadas. Segundo Dubet (1994, p. 53): “A ideia de sociedade foi sempre identificada com a de modernidade e a de evolução, sendo a sociedade a forma da organização social moderna inscrita numa evolução necessária. O conceito de sociedade articulava uma teoria da ordem com uma teoria da mudança”. A sociedade tinha como principal traço o Estado e suas instituições modernas. As instituições, ao mesmo tempo em que garantiam a integração dos indivíduos, também influenciavam suas ações e comportamentos.

Dubet (1994) vai dizer que a relação entre a sociedade, o Estado e suas instituições só pode ser vista como algo socialmente construído. Assim, a noção de sociedade estaria ligada a ideia de conflito onde os indivíduos, ao lançarem mão de diversas lógicas de ação, vão constituindo experiências sociais que desaguam em relações de igualdade/desigualdade. Desse modo, quanto mais se perpetua a ideia de igualdade, mais se fortalece a meritocracia e se segmentam as relações entre os indivíduos. A ação social, nesse viés, deixa de ser pensada como algo unitário, racional e estratificado, passando a ser vista pelas relações conflituosas, heterogêneas e múltiplas.

Para Dubet (1994), a ideia de sociedade está se enfraquecendo junto ao projeto de ordem, totalidade e progresso da modernidade. A defesa de uma sociedade unificada e industrial (promulgada pela Sociologia clássica) não atrai mais a vida contemporânea. Os movimentos de lutas de classe se enfraqueceram e, consequentemente, abriram espaços para outros tipos de lutas sociais “fragmentadas” e particulares, como as questões de raça e de gênero.

Nesse sentido, são as “novas” relações entre os sujeitos e as instituições (que perdem o monopólio que outrora obtinham) e os novos cenários heterogêneos de socialização que irão fundamentar a experiência social para Dubet, ou seja, uma experiência social pautada pelas atividades 
heterogêneas dos sujeitos, às quais conferem sentido para suas diferentes práticas. Agora, a sociedade volta-se menos para seus fatores socialmente construídos e mais para aquelas experiências sociais que os atores desenvolvem cotidianamente. Wautier (2003) vai dizer que na sociedade contemporânea o indivíduo, pelas suas experiências sociais, se reconhece cada vez mais de forma autônoma, entendendo que é livre para tomar suas decisões, bem como viver constantemente em conflitos e tensões.

\begin{abstract}
Descobre-se outra ideia de sociedade, caracterizada pela justaposição de elementos heterogêneos, pela separação das esferas econômicas e culturais, proporcionando o surgimento da subjetividade no cotidiano. A experiência social, como maneira de perceber o mundo, é "uma construção inacabada de sentido", que permite de "se construir", através do conflito e do engajamento na ação coletiva e de "construir o mundo social” através de uma combinação de logicas diferentes (WAUTIER, 2003, p. 192).
\end{abstract}

Na esteira das transformações globalizantes ocorridas no contemporâneo, Wautier (2003) vai dizer que, para Dubet, o sentido da experiência atualmente não é mais dado nem pela vida social e muito menos pela unidade do sistema, mas sim, pelo produto de uma atividade. O próprio Dubet (1994, p. 107) ressalta que,

A sociologia da experiência tem em vista definir a experiência como uma combinação de lógicas de ação, lógicas que ligam o ator a cada uma das dimensões de um sistema. O ator é obrigado a articular logicas de ação diferentes, e é a dinâmica gerada para cada atividade que constitui a subjetividade do ator e a sua reflexividade.

No que tange a experiência, Dubet (1997) lecionou disciplinas de história e geografia durante um ano em um colégio francês. O que motivou o sociólogo a vivenciar essa experiência foi o fato de que ele viu a necessidade de enxergar, enquanto professor, todas as dificuldades que eram relatadas a ele (em suas pesquisas) por outros professores. Outra razão para Dubet adentrar nesse “mundo”, foi o fato de, em uma ocasião, ter sido apontado como um intelectual que via os problemas do cotidiano escolar apenas de forma abstrata por nunca ter lecionado.

As conclusões chegadas por Dubet após um ano ensinando crianças e jovens foi a de que a realidade educacional, no que tange a relação dos professores e alunos, é complexa. Dubet (1997) “descobriu” que em uma hora de aula, apenas 20 minutos são reservados para o ensino da matéria, o resto do tempo serve para organizar o espaço e “botar ordem” na sala. Além disso, o sociólogo destacou que o maior problema das escolas (pelo menos naquela em que ele lecionou) não é a violência, mas sim, achar um meio para fazer com que os alunos se interessem, ouçam e se comportem dentro da sala de aula. A saída, então, é fazer com que a escola seja um espaço de normatividade e de 
liberdade onde ainda sim pautados por regras, os alunos possam se educar em outros espaços que não apenas a sala de aula, fazendo com que se interessem mais e que os professores tenham condições de dar aulas normalmente.

Esta experiência fez Dubet perceber a escola de outro modo. Além de reconhecer que as falas dos professores realmente eram corretas em suas pesquisas anteriores, Dubet (1997) definiu que é praticamente impossível ser observador e professor ao mesmo tempo. Para ele, o professor, em virtude da complexidade de sala de aula, só consegue dar aula. De que maneira, então, a partir da “experiência” (a Sociologia da experiência e sua experiência como professor), Dubet vai pensar a escola? De que maneira as análises de Dubet sobre a sociedade e a escola se relacionam com o campo da EF (escolar)?

\section{AS REFERÊNCIAS DE FRANÇOIS DUBET NA EDUCAÇÃO FÍSICA}

Foi realizado, no presente texto, um levantamento bibliográfico com a intenção de compreender como Dubet é referenciado no campo da EF, em termos de artigos científicos. Para Galvão (2010, p.1) realizar um levantamento bibliográfico é: revisar o conhecimento produzido em uma determinada área, potencializar intelectualmente este conhecimento e propor novos caminhos,

[...] a fim de: evitar a duplicação de pesquisas, ou quando for de interesse, reaproveitar e replicar pesquisas em diferentes escalas e contextos; observar possíveis falhas nos estudos realizados; conhecer os recursos necessários para a construção de um estudo com características específicas; desenvolver estudos que cubram lacunas na literatura trazendo real contribuição para a área de conhecimento; propor temas, problemas, hipóteses e metodologias inovadores de pesquisa [...]

O levantamento foi construído a partir de dois objetivos: 1) mapear, de maneira quantitativa, o número de referências de Dubet e; 2) diagnosticar, qualitativamente, como a teoria deste sociólogo tem sido utilizada no campo da EF. As revistas foram escolhidas a partir da classificação Webqualis/CAPES. Nesse sentido, na esteira de Bungenstab (2018, p. 781), foi realizado um primeiro mapeamento a fim de identificar as 10 revistas oriundas do campo da EF com as melhores avaliações. Percebeu-se que não há nenhuma revista avaliada como A1; uma revista (Revista Movimento) avaliada como A2; cinco revistas (Motricidade, Motriz, RBCE, Revista Brasileira de Educação Física e Revista de Educação Física da UEM) avaliadas como B1 e quatro periódicos (Licere, Motrivivência, Pensar a Prática e Revista Brasileira de Atividade Física e Saúde) avaliados como B2. A partir disto, foram utilizados quatro critérios para escolha das revistas a serem pesquisadas: 1) que estabelecessem diálogo com o campo das Ciências Humanas e da Sociologia; 2) que publicassem seus artigos 
originalmente em língua portuguesa; 3) com estratos qualis/CAPES diferentes, ou seja: pelo menos uma revista de cada estrato, levando em consideração a heterogeneidade dos periódicos e entendendo que há produção de qualidade em revistas de estratos “inferiores” e, 4) revistas que atualmente tem publicações quadrimestrais (BUNGENSTAB, 2018, p. 781).

Após essa seleção foram escolhidas quatro revistas: Revista Motrivivência, RBCE, Pensar a Prática e Revista Movimento. Inicialmente foram mapeados aqueles artigos que fizeram referência à Dubet a partir do ano de 2001 até o ano de 2017. Esse mapeamento se deu por meio de uma busca profunda analisando o referencial teórico de todos os 2889 artigos publicados ${ }^{3}$ (quadro 1). Após essa consulta foram identificados 13 textos que utilizaram Dubet em suas referências. Neste momento o foco voltou-se para a análise qualitativa e a realização da leitura completa destes 13 textos oportunizou a compreensão de como Dubet foi citado, sobretudo no que tange aos diálogos que os autores dos textos estabelecem (ou não) com sua obra. Com esta análise o leitor perceberá, a seguir, que Dubet é utilizado pelo campo da EF de três maneiras: 1) como leitura pontual da escola e da sociedade hodierna; 2) para discutir sobre os sentimentos de (in)justiça e 3) como leitura profunda no diálogo com as experiências formativas.

Quadro 1: Número de referências de François Dubet encontradas em cada periódico a partir do século XXI

\begin{tabular}{|c|c|c|c|c|c|}
\hline Ano/Periódicos & Motrivivência & $\begin{array}{c}\text { Pensar a } \\
\text { Prática }\end{array}$ & $\begin{array}{c}\text { Revista } \\
\text { Movimento }\end{array}$ & RBCE & TOTAL \\
\hline $\begin{array}{c}\text { Referências à Dubet } \\
\text { de 2001 até 2017 }\end{array}$ & 1 & 3 & 9 & 0 & 13 \\
\hline $\begin{array}{c}\text { Total de publicações } \\
\text { de 2001 até } 2017^{4}\end{array}$ & 556 & 694 & 840 & 799 & 2.889 \\
\hline
\end{tabular}

Fonte: construção do autor

Percebe-se, de acordo com o quadro acima, que apenas treze artigos citaram Dubet em suas pesquisas. Isso nos permite concluir que no século XXI a teoria desenvolvida pelo sociólogo francês foi pouco utilizada (em termos quantitativos) pelo campo da EF. Se analisarmos de maneira percentual nota-se que Dubet foi referenciado em apenas $0.44 \%$ do total de artigos publicados nestes quatro periódicos. ${ }^{5}$ Num primeiro movimento analítico poderíamos afirmar que a teoria desenvolvida por Dubet não é utilizada pela EF, pois o que esse autor descreveu sobre a sociedade não faz relação direta com as discussões travadas neste campo, principalmente aquela debatida no cenário brasileiro.

\footnotetext{
${ }^{3}$ Para a realização desta tarefa foi necessário ir até o referencial teórico de cada artigo. Este trabalho permitiu afirmar com precisão o número exato de referências feitas à Dubet.

${ }^{4}$ As resenhas não foram incluídas.

5 Vale acentuar, também, o destaque da revista Movimento que publicou 69\% de todos os artigos mapeados nos quatro periódicos.
} 
Por outro lado, poderíamos também supor que a pouca relação entre Dubet e a EF se deve ao fato de esta última ainda não ter aprofundado suas leituras deste sociólogo? Para responder esta pergunta é necessário realizamos análises qualitativas dos artigos, pois o fato de este sociólogo ter sido pouco referenciado não significa que os usos de sua teoria foram realizados de forma superficial.

A obra mais citada de Dubet é o livro "Sociologia da Experiência”, sendo referenciada sete vezes. Os livros “Desigualdades multiplicadas” e “O que é uma escola justa?” foram citados duas vezes cada. Já o artigo “Integração: quando a sociedade nos abandona” e os livros “ La gálere” e “Repensar a justiça social” foram citados uma vez cada. A partir disso, percebemos que Dubet foi utilizado pelo campo da EF por meio de três vieses: 1) como leitura geral; 2) Leitura pontual e 3) como leitura específica.

Quadro 2: Tipo de leitura realizada pela EF a partir do diálogo com a teoria de Dubet

\begin{tabular}{|c|c|r|r|}
\hline Leitura geral & Leitura pontual & Leitura específica & TOTAL \\
\hline $5(38 \%)$ & $2(16 \%)$ & $6(46 \%)$ & $13(100 \%)$ \\
\hline
\end{tabular}

Fonte: construção do autor

Como leitura geral, estou entendendo aquelas referências que utilizaram Dubet de maneira generalizada para classificar a escola e a sociedade hodierna; como leitura pontual destacam-se aqueles artigos que procuraram discutir sobre os sentimentos de (in)justiça e; como leitura específica os textos que se preocuparam em estabelecer diálogo com a categoria das experiências formativas.

Bossle, Neto e Wittizorecki (2013), Thomassim (2007), Conceição e Molina Neto (2017) e Bungenstab e Almeida (2016) citam Dubet (2003, 2008) de maneira geral para refletirem sobre as transformações sociais que afetam as instituições e, também, a escola atual. Por exemplo, Bossle, Neto e Wittizorecki (2013, p. 56) dizem que:

A perda da "autoridade da escola" e o "desinteresse" são fenômenos intimamente relacionados com a perspectiva do lugar que a escola assume na modernidade líquida (rapidamente lembramos que as novas tecnologias da informação e da comunicação rivalizam com a escola na oferta de informação): sólida, engessada e vulnerável aos anseios de uma lógica individualista e meritocrática (DUBET, 2003; 2008), pautada pela agenda de manutenção de uma ordem imposta de fora [...]

Para ser uma instituição, segundo Dubet (1994, 2006), a escola comportava de modo hierárquico essas funções, formando um bloco integrado. O sociólogo francês, baseando-se por exemplos de seu País, vai dizer que, enquanto educação, a escola possuía (possui) e era detentora de um determinado tipo de conhecimento que apenas ela seria capaz de transmitir. Conhecimento esse que perpassava os saberes técnicos, se importando mais com questões culturais e artísticas, fazendo 
do professor um tipo de mestre que pautava seu prestígio por ser detentor de um conhecimento “sagrado”.

A seleção também se apresentava como uma função ímpar para a manutenção da instituição escolar. Não eram todos que tinham a oportunidade de conquistar um diploma. Muitos indivíduos (quase sempre o das classes menos favorecidas e filhos de operários) tinham seus processos de escolaridade interrompidos e apenas os "mais dotados” alcançavam os níveis mais altos de estudos por meio de bolsas. Desse modo, a escola mantinha de forma segura a dominação sobre quais indivíduos seriam selecionados a ocupar essa ou aquela função social específica. Segundo Dubet (1994, p. 174), a importância que a escola tinha para socializar os indivíduos fazia com que:

As expectativas dos professores, dos alunos e das suas famílias eram ajustadas, a tal ponto que se formou pouco a pouco a imagem de uma idade de ouro escolar. Idade de ouro acerca da qual é, no entanto, necessário lembrar que implicava uma forte segregação social quanto à escola, o fecho da escola sobre si mesma e uma grande distância nas relações entre os professores e os alunos.

Nesse sentido, a escola funcionava como uma instituição socializadora, aparelho do Estado, que perpetuava um determinado modelo de sociedade, caracterizada por valores, normas e regras gerais, mas também específicas para cada indivíduo. Para Dubet (1994), no entanto, as funções pilares que sustentavam a escola foram perdendo força gradual, ao passo que a sociedade também se modificou. Conceição e Molina Neto (2017) vão discutir a respeito da construção das identidades docentes na escola contemporânea. Lançando mão das análises de Dubet e Martucelli (1997) eles dizem que tornar-se professor é um processo que envolve todo o percurso docente no que tange as diversas experiências formativas, como também aos tipos de coletividades que são assumidas dentro da escola.

Dois trabalhos são fundamentais para compreender a experiência dos atores (professores e alunos) na instituição escolar pelas lentes de Dubet. O primeiro deles (Dubet; Martuccelli, 1996), em parceria com Danilo Martuccelli, objetivou captar as experiências dos estudantes nas escolas francesas. Este trabalho oportunizou a Dubet compreender como as lógicas de ação são operadas na prática escolar, podendo ser caracterizadas pelas lógicas de integração (experiência escolar construída a partir das identificações com o professor e a normas), pelos processos de socialização/subjetivação (momento de questionamento daquilo que a escola propõe) e pelos momentos de exclusão (desinteresse pela escola e aceitação do fracasso escolar). 
Como bem ressaltou Giovanini (2011), Dubet e Martuccelli (1996, 1997) conseguiram demonstrar que a experiência escolar é caracterizada por constantes momentos de desigualdades. ${ }^{6}$ Essas desigualdades, de acordo com o próprio Dubet (2003), deslocaram os intelectuais da educação para as análises das questões internas da escola, sobretudo, aquelas de ordem microssocial. É nesse bojo que Dubet (2003), enxergando a escola como uma instituição meritocrática, afirma que diante das experiências desiguais e excludentes os alunos adotam duas condutas: de retraimento e/ou de conflito.

O retraimento diz respeito àqueles estudantes que não obtém resultados honrosos e acabam por aceitar suas condutas malsucedidas, abandonando, assim, os ritos escolares. Já a opção pelo conflito, segundo Dubet (2003), se caracteriza pela presença da violência que pode ser vivenciada fisicamente (por meio de roubos e agressões) ou simbolicamente, quando os estudantes procuram contestar as ordens características da escola (praticando insultos, se vinculando a outras instituições).

Para Dubet (1994), a escola não está passando por uma crise, mas sim, vivenciando o fim de um modelo de organização concebido como ferramenta para institucionalizar valores. No entanto, não se pode afirmar que a escola não funciona mais e que chegou o seu fim, o sociólogo francês ressalta que a escola continua funcionando, porém, não mais como uma instituição. Vê-se, a partir desta relação estabelecida com Dubet, que o sociólogo francês assume um lugar pontual nas produções da área, uma vez que não ajuda profundamente nas reflexões e objetivos estabelecidos pelos textos dos autores supracitados, situando-se apenas no que tange a um tipo de caracterização da escola contemporânea.

A segunda leitura realizada a partir das obras de Dubet refere-se ao debate sobre as (in)justiças sociais. Discutindo os sentimentos de (in)justiça Damico (2013, p. 21) analisa as manifestações de esporte e lazer no subúrbio francês, fazendo referência a Dubet (2003b) ao descrever sobre o sentimento de justiça que o esporte promove entre seus praticantes:

Para produzir sujeitos autogovernados, as artes marciais fazem uso de toda uma metodologia de saberes que vão desde as cores das faixas - que diferenciam seus praticantes pelo nível de aprendizado - a códigos de conduta durante treinos e competições, código de honra que interdita as lutas fora das arenas próprias para esse uso, categorias divididas em função do peso e da idade dos praticantes, que conduz ao que François Dubet (2003) define como a ficção da justiça no âmbito esportivo. Ou seja, há toda uma utilização de tecnologias disciplinares para a normalização e o desenvolvimento adequado de seus praticantes.

6 Segundo Dubet (2003b), a multiplicação de suas desigualdades faz com que os atores percebam o espaço escolar de um modo muito mais contraditório, pois, ao passo que a escola defende a igualdade de acesso, ela passa a diferenciar e classificar os sujeitos que lá estão: tornando-os desiguais. 
Ainda segundo Damico (2013), a falsa sensação de justiça promovida pelo esporte a partir de seus códigos e regras justifica as relações de dominação entre os praticantes. Desse modo, o esporte acaba por diferenciar os dominantes (vencedores) dos dominados (perdedores) e os falsos sentimentos de justiça estabelecidos pela lógica esportiva nesse processo o mantém intacto. Baptista e Baptista (2017, p. 212) também utilizam os pensamentos de Dubet (2004) no que tangem a sua teoria da justiça abordando historicamente os processos de ingresso em cursos de EF que tiveram os testes físicos como requisitos básicos:

Em nome da busca da justiça como equidade aqui delineada, notou-se que a exigência de competências mínimas, embora razoável em quaisquer processos avaliativos, colidia com o próprio processo de construção identitária da Educação Física. Esse processo tornou-se ambíguo e múltiplo a partir das transformações que acometeram a área, sobretudo nos anos 1970 e 1980.

Segundo os autores, o próprio campo da EF reconheceu que é preciso privilegiar os saberes plurais da área para além dos testes de aptidão física. Ademais, os professores que ainda acreditam que os testes (ou o desempenho prático) são fundamentais para a área, eliminam a possibilidade de outros indivíduos (estudantes) terem acesso a este conhecimento. Nesse sentido, Dubet (2004) auxiliou Baptista e Baptista (2017) na reflexão sobre a redução das injustiças no que tange aos limites possibilidades dos testes de aptidão física como forma de ingresso no ensino superior.

Dubet $(2008,2011)$ propõe que a sociedade se torne mais equitativa, entendendo que, infelizmente, a instituições (inclusive as esportivas e educacionais) são lugares que favorecem determinados tipos de indivíduos. Para ele é preciso desenvolver uma "igualdade distributiva de oportunidades” (2008, p. 12). Em segundo lugar Dubet ressalta a importância de se trabalhar a igualdade de oportunidades menos no sentido da meritocracia e mais no intuito da experiência e da partilha, ou seja, uma desvalorização da competição e do “vencedor”. Para Dubet (2008, p. 39):

O percurso escolar é construído como um torneio de tênis no qual cada concorrente tem a possibilidade de sair vencedor contanto que não perca nenhum match. Formalmente, todos os concorrentes são considerados iguais, -e às vezes ocorre que os jogadores menos reputados acabam por triunfar graças à "gloriosa incerteza do esporte". De outro lado, como toda a escola, a escola da igualdade das oportunidades classifica, orienta e hierarquiza os alunos em função de suas performances. A competição escolar torna, portanto, os alunos necessariamente desiguais.

As análises que Dubet realiza sobre a justiça escolar apontam caminhos para a reflexão a respeito da presença da justiça nas instâncias esportivas e na EF escolar. Ora, se a escola está pautada por uma lógica de justiça que separa os estudantes entre vencedores e vencidos, essa lógica também 
pode afetar suas disciplinas escolares. O que se pode afirmar a partir desta relação estabelecida com o debate sobre justiças e a EF é que Dubet ajudou os autores a compreenderem que os sentimentos de justiça muitas vezes são internalizados pelos indivíduos, fazendo com que eles aceitem as regras do sistema.

Por sua vez, o terceiro tipo de leitura feita pelo campo da EF refere-se ao debate sobre as experiências sociais e formativas. Clates e Gunther (2015) e Oliveira Diehl et al (2017, p.184) fazem uso de Dubet (1994) para falarem sobre a "sociologia da experiência”, mais precisamente abordando a importância da experiência na formação inicial de professores de EF.

François Dubet, em seu livro Sociologia da Experiência, contribui para a compreensão das experiências docentes e de socialização vivenciadas no mundo atual. O conceito de experiência social elaborada por Dubet (1994) abrange dois aspectos importantes: práticas sociais e as lógicas de ação. Para esse autor a experiência social é crítica porque implica num trabalho reflexivo do sujeito diante do papel das normas sociais. Portanto, entendemos que além de concretizarem a ação corporal proposta pelo docente nas aulas de Educação Física, os estudantes precisam refletir e se posicionar, criticamente sobre o que estão realizando, possibilitando-os construir e reconstruir o sentido que essas ações corporais adquire na prática social desses sujeitos.

No que concernem às experiências formativas, vale a pena destacar as reflexões pioneiras desenvolvidas por Figueiredo $^{7}(2004,2008,2010)$ com o intuito de aproximar a obra de Dubet junto ao campo da EF a partir da ideia de experiências sociocorporais.

[...] notamos, que a relação dos alunos com os saberes curriculares é bastante regulada por suas experiências sociocorporais vividas anteriormente e produz ações específicas como valorizações e hierarquizações decorrentes de elementos inscritos subjetivamente em suas identidades. Em síntese, pode-se dizer que há uma conexão intrínseca entre as experiências dos alunos e suas relações com o saber. (FIGUEIREDO, 2004, p. 97)

Com base nas diferentes definições sobre a ação mencionadas por Dubet (1994), essa ação individual de auto-exclusão dos alunos das aulas produz determinadas experiências sociocorporais na Educação Física e pode ser pensada como resultado de uma interação (modelo da comunicação) em que os alunos se relacionam com o professor, com outros alunos e com os saberes. Nessa interação, a ação de se auto excluir pode ser compreendida como uma maneira de manifestar a não identificação com aquele saber ou com a forma como ele está sendo desenvolvido e, também, como estratégia (modelo da ação racional) diante de alguma dificuldade ou de falta de interesse, não previamente decidida e que pode ser redefinida em meio ao desenvolvimento das aulas. (FIGUEIREDO, 2008, p. 92)

7 Aliás, ressaltasse que Zenólia Figueiredo é a autora que mais citou Dubet no século XXI, aparecendo como autora (e coautora) em quatro dos treze artigos mapeados. 
Nesse sentido, Figueiredo (2008) passa a realizar análises de estudantes do curso de EF a partir de duas categorias anteriormente elencadas por Dubet (1994): a prática social e as lógicas de ação. É a partir deste diálogo que Figueiredo (2010) reconhece que o corpo também é constituído socialmente e que as experiências corporais podem incidir nas trajetórias futuras dos professores de EF. Vale ressaltar que essas experiências podem tanto ser positivas como negativas na construção das identidades docentes. Nesse sentido, Figueiredo $(2004,2008)$ nos convida a realizarmos reflexões a respeito de como os estudantes que cursam EF conseguem enxergam (ou não) seus processos formativos profissionais. Tal fato está relacionado às experiências individuais (sociocorporais) trazidas pelos estudantes desde a educação básica, sobretudo, no que tange as representações que estes possuem sobre o que é o curso e suas disciplinas. Deste modo, percebemos uma relação significativa com Dubet, uma vez ele contribui para pensar a formação inicial, bem como as diversas experiências sociocorporais que os profissionais da área desenvolvem em suas ações. No entanto, quais poderiam ser as outras contribuições que este importante sociólogo francês ainda pode oportunizar para o campo da EF e para futuras pesquisas?

\section{CONCLUSÕES}

O objetivo deste artigo foi o de mapear e analisar como François Dubet tem sido utilizado pelo campo da EF e quais possíveis contribuições que as reflexões deste sociólogo ainda podem trazer para nossa área. O que vimos, a partir das análises da produção científica em quatro revistas especializadas na área, é que Dubet tem figurado no campo de três modos diferentes. O primeiro, mais geral, não estabelece uma relação “epistemológica” com o campo da EF e, nesse caso, o diálogo não alcança a profundidade necessária; ao contrário, Dubet parece surgir muito mais no sentido de oferecer uma “segurança ontológica” entres os pesquisadores da área.

Já o segundo e o terceiro modo mostram uma relação mais profunda com Dubet, sobretudo a partir do momento que os autores da EF tentam operar com seus conceitos e ideias, como aquelas referentes à (in)justiça social e as lógicas de ação das experiências sociais. Sem dúvida, estes modos de usar Dubet contribuem para o debate no campo da EF, evitando reducionismos e nos colocando em constante diálogo com novos vocabulários (Almeida, Bracht e Vaz, 2012).

Em relação à manutenção/continuidade de diálogos com Dubet, concordamos com as conclusões de Diehl, Wittizorecki e Molina Neto (2017) e de Figueiredo (2004) quando eles reconhecem que a obra de Dubet pode ajudar a pensar a experiência como categoria fundamental para a formação docente e discente, não só influenciando nas escolhas profissionais, mas também 
incidindo na trajetória formativa de crianças e jovens estudantes da educação básica. Podendo, portanto, serem enriquecidas e/ou empobrecidas na construção das identidades corporais.

Todas essas reflexões podem ser problematizadas se nos debruçarmos sobre a obra de Dubet e continuarmos na busca de diálogo com este sociólogo. Trata-se de um referencial teórico pertinente para a área e o investimento é válido.

\section{REFERÊNCIAS}

ALMEIDA, Felipe Quintão; BRACHT, Valter; VAZ, Alexandre. Classificações epistemológicas na Educação Física: redescrições.... Movimento, Porto Alegre, v.18, n. 4, p. 241-263, ago. 2012.

BAPTISTA, Guilherme Gonçalves; BAPTISTA, Juliana Gonçalves. Os testes de aptidão física na Educação Física: da justiça como equidade ao direito à educação. Pensar a Prática, v. 20, n.1, mar. 2017.

BOURDIEU, Pierre; PASSERON, Jean Claude. A reprodução: elementos para uma teoria do sistema de ensino. 7 ed. Petrópolis: Vozes, 2014.

BOSSLE, Fabiano; MOLINA NETO, Vicente; WITTIZORECKI, Evandro Schultz. Sobre "a vida como ela é”: os professores de Educação Física e as violências na escola pública municipal de Porto Alegre. Movimento, Porto Alegre, v. 19, n. 4, p. 47-67, 2013.

BUNGENSTAB, Gabriel Carvalho. A presença de Anthony Giddens na produção científica da educação física brasileira: entre a reflexão e o deslize. Movimento, v. 24, n. 3, p. 777-788, jul./ set., 2018.

BUNGENSTAB, Gabriel Carvalho; ALMEIDA, Felipe Quintão de. Práticas corporais nas escolas de ensino médio situadas em Vitória/Espírito Santo. Pensar a Prática, Goiânia, v. 19, n. 1, jan./mar. 2016.

COLETIVO DE AUTORES. Metodologia do Ensino de Educação Física - $2^{a}$ Edição Revista. São Paulo: Cortez, 2009.

CONCEIÇÃO, Victor Julierme Santos da; MOLINA NETO, Vicente. A cultura escolar sob o olhar do paradigma da complexidade: um estudo etnográfico sobre a construção da identidade docente de professores de educação física no início da docência. Movimento (ESEFID/UFRGS), Porto Alegre, v. 23, n. 3, p. 827-840, set. 2017.

CLATES, Daniela de Moura; GÜNTHER, Maria Cecília Camargo. O PIBID e o percurso formativo de professores de Educação Física. Motrivivência, Florianópolis, v. 27, n. 46, p. 53-68, nov. 2015.

DAMICO, José. GESTÃO DA VIDA A PARTIR DO ESPORTE E LAZER EM GRIGNY CENTRE - FRANÇA. Movimento (ESEFID/UFRGS), Porto Alegre, v. 19, n.1, p. 11-31, out. 2012. 
DAYRELL, Juarez. A escola faz juventudes? Reflexões em torno da socialização juvenil. Ed. Soc., Campinas, vol. 28, n. 100 - Especial, p. 1105-1128, out. 2007.

DIEHL, Vera Regina Oliveira; WITTIZORECKI, Elisandro Schultz; MOLINA NETO, Vicente. Estado do Conhecimento: a categoria experiência no âmbito da Educação Física. Goiânia: Pensar a Prática, v. 20, n. 1, mar. 2017.

DUBET, François; MARTUCCELLI, Danilo. A l’école. Sociologie de l’expérience scolaire. Paris: Éditions Seuil, 1996.

DUBET, François. Sociologia da Experiência. Lisboa: Instituto Piaget, 1994.

DUBET, François. Quando o sociólogo quer saber o que é ser professor: entrevista com François Dubet. Revista Brasileira de Educação, n. 5, p. 222 - 231, jul/ago. 1997. Disponível em: http://educa.fcc.org.br/scielo.php?pid=S1413-24781997000200018\&script=sci_arttext Acesso em 22 nov. 2018.

DUBET, François. A escola e a exclusão. Cadernos de Pesquisa, n. 119, p. 29-45, jul. 2003.

DUBET, François. Desigualdades multiplicadas. Ijuí, RS: Unijuí, 2003b.

DUBET, François. O que é uma escola justa? Cadernos de Pesquisa, v. 34, n. 123, p. 539 - 555, set/dez. 2004.

DUBET, François. El declive de la institución - profesiones, sujetos e individuos ante la reforma del Estado. Barcelona: Gedisa, 2006.

DUBET, François. O que é uma escola justa? A escola das oportunidades. São Paulo: Cortez, 2008.

DUBET, François. Repensar la justicia social: contra el mito de la igualdade de oportunidades. Buenos Aires: Siglo XXI, 2011.

DUBET, François. Os limites da igualdade de oportunidade. Cadernoscenpec, São Paulo, vol. 2, n. 2, p. 172-179, dez. 2012. Disponível em:

http://cadernos.cenpec.org.br/cadernos/index.php/cadernos/article/view/187/215. Acesso em 6 nov. 2018.

DURKHEIM, Emile. Educação e Sociologia. 2 ed. Rio de Janeiro: Vozes, 2011.

FIGUEIREDO, Zenólia Cristina. Formação docente em educação física: experiências sociais e relação com o saber. Movimento, Porto Alegre, v. 10, n. 1, p. 89-111.jan./abr. 2004.

FIGUEIREDO, Zenólia Cristina. Experiências sociocorporais e formação docente em educação física. Movimento, Porto Alegre, $n^{\circ}$ 14, pp. 85-110. 2008.

FIGUEIREDO, Zenólia Cristina. Experiências profissionais, identidades e formação docente em educação física. Revista Portuguesa de Educação, Braga, v. 23, n. 2, p. 153-171, jul./dez. 2010. 
GALVÃO, Maria Cristiane Barbosa. O levantamento bibliográfico e a pesquisa científica. In: FRANCO, Laércio Joel, PASSOS Afonso Dinis Costa. (Org.). Fundamentos de epidemiologia. São Paulo: Manole, p. 377, 2010.

GIOVANNI, Luciana Maria. François Dubet: a experiência escolar em jogo. In: REGO, Teresa Cristina. (Org.). Educação, Escola e Desigualdade. Petrópolis/São Paulo: Vozes/Segmento, 2011.

KRAWCZYK, Nora. Uma roda de conversa sobre os desafios do ensino médio. In: DAYREL, Juarez.; CARRANO, Paulo Cesar; MAIA, Carla Linhares. (orgs). Juventude e ensino médio: sujeitos e currículos em diálogo. Belo Horizonte, Editora da UFMG, 2014.

NOGUEIRA, Maria Alice. A sociologia da educação no final dos anos 60/início dos anos 70: o nascimento do paradigma da reprodução. Em Aberto, n. 46, p. 49-58, abr./jun, 1990.

SANTOS, Boaventura Souza. Um discurso sobre as ciências. $7^{\circ}$ Ed. São Paulo: Cortez, 2010.

THOMASSIM, Luís Eduardo Cunha. Os sentidos da exclusão social na bibliografia da Educação Física brasileira. Movimento, Porto Alegre, v. 10, n. 2, p. 105-122, jan./abr. 2007.

WAUTIER, Anne Marie. Para uma Sociologia da Experiência. Uma leitura contemporânea: François Dubet. Sociologias. Porto Alegre, $n^{0}$ 09, p. 174-214, jun. 2003. Disponível em: http://www.scielo.br/pdf/soc/n9/n9a07.pdf. Acesso em: 25 nov. 2018.

\section{NOTAS DE AUTOR}

\section{AGRADECIMENTOS}

Não se aplica.

\section{CONTRIBUIÇÃO DE AUTORIA}

Não se aplica.

\section{FINANCIAMENTO}

Não se aplica.

\section{CONSENTIMENTO DE USO DE IMAGEM}

Não se aplica.

\section{APROVAÇÃO DE COMITÊ DE ÉTICA EM PESQUISA}

Não se aplica.

\section{CONFLITO DE INTERESSES}

Não há conflito de interesses. 


\section{LICENÇA DE USO}

Os autores cedem à Motrivivência - ISSN 2175-8042 os direitos exclusivos de primeira publicação, com o trabalho simultaneamente licenciado sob a Licença Creative Commons Attribution NonComercial ShareAlike (CC BY-NC SA) 4.0 International. Estra licença permite que terceiros remixem, adaptem e criem a partir do trabalho publicado, desde que para fins não comerciais, atribuindo o devido crédito de autoria e publicação inicial neste periódico desde que adotem a mesma licença, compartilhar igual. Os autores têm autorização para assumir contratos adicionais separadamente, para distribuição não exclusiva da versão do trabalho publicada neste periódico (ex.: publicar em repositório institucional, em site pessoal, publicar uma tradução, ou como capítulo de livro), com reconhecimento de autoria e publicação inicial neste periódico, desde que para fins não comerciais e compartilhar com a mesma licença.

\section{PUBLISHER}

Universidade Federal de Santa Catarina. Programa de Pós-Graduação em Educação Física. LaboMídia - Laboratório e Observatório da Mídia Esportiva. Publicado no Portal de Periódicos UFSC. As ideias expressadas neste artigo são de responsabilidade de seus autores, não representando, necessariamente, a opinião dos editores ou da universidade.

\section{EDITORES}

Mauricio Roberto da Silva, Giovani De Lorenzi Pires, Rogério Santos Pereira.

\section{HISTÓRICO}

Recebido em: 18 de maio de 2018.

Aprovado em: 31 de julho de 2018. 